\title{
Q Young adult sequelae of adolescent cannabis use: an integrative analysis
}

\author{
Edmund Silins, L John Horwood, George C Patton, David M Fergusson, Craig A Olsson, Delyse M Hutchinson, Elizabeth Spry, \\ John W Toumbourou, Louisa Degenhardt, Wendy Swift, Carolyn Coffey, Robert J Tait, Primrose Letcher, Jan Copeland, Richard P Mattick, \\ for the Cannabis Cohorts Research Consortium*
}

\section{Summary}

Lancet Psychiatry 2014;

1: $286-93$

See Comment page 249

*Other members listed at end of paper

National Drug and Alcohol Research Centre (E Silins PhD, D M Hutchinson PhD, Prof L Degenhardt PhD, W Swift PhD, R P Mattick PhD) and National Cannabis Prevention and Information Centre (Prof J Copeland PhD), UNSW Australia, Sydney, NSW, Australia; Christchurch Health and Development Study Department of Psychological Medicine, University of Otago,

Christchurch, New Zealand (L) Horwood MSc, Prof D M Fergusson PhD); Centre for Adolescent Health, Murdoch

Childrens Research Institute,

Royal Children's Hospital,

Melbourne, VIC, Australia (Prof GC Patton MD,

CA Olsson PhD, E Spry BA,

ProfJWToumbourou PhD,

Prof L Degenhardt, (Coffey PhD);

School of Psychology, Deakin

University, Geelong, VIC, Australia (CA Olsson, ProfJWToumbourou); School of

Population and Global Health

(Prof L Degenhardt) and

Department of Paediatrics

(Prof GC Patton, CA Olsson, $\mathrm{P}$ Letcher PhD) and Psychological Sciences (CA Olsson), University of Melbourne, Melbourne, VIC, Australia; Department of Global Health, School of Public Health,

University of Washington, Seattle, WA, USA

(Prof L Degenhardt); National Drug Research Institute, Faculty

of Health Sciences, Curtin University, Perth, WA, Australia (RJTait PhD); Centre for Research on Ageing Health and Wellbeing, Australian National University, Canberra, ACT, Australia (RJTait)

Correspondence to:

Dr Edmund Silins, National Drug and Alcohol Research Centre, UNSW Australia, Sydney, NSW 2052, Australia e.silins@unsw.edu.au

Background Debate continues about the consequences of adolescent cannabis use. Existing data are limited in statistical power to examine rarer outcomes and less common, heavier patterns of cannabis use than those already investigated; furthermore, evidence has a piecemeal approach to reporting of young adult sequelae. We aimed to provide a broad picture of the psychosocial sequelae of adolescent cannabis use.

Methods We integrated participant-level data from three large, long-running longitudinal studies from Australia and New Zealand: the Australian Temperament Project, the Christchurch Health and Development Study, and the Victorian Adolescent Health Cohort Study. We investigated the association between the maximum frequency of cannabis use before age 17 years (never, less than monthly, monthly or more, weekly or more, or daily) and seven developmental outcomes assessed up to age 30 years (high-school completion, attainment of university degree, cannabis dependence, use of other illicit drugs, suicide attempt, depression, and welfare dependence). The number of participants varied by outcome ( $\mathrm{N}=2537$ to $\mathrm{N}=3765)$.

Findings We recorded clear and consistent associations and dose-response relations between the frequency of adolescent cannabis use and all adverse young adult outcomes. After covariate adjustment, compared with individuals who had never used cannabis, those who were daily users before age 17 years had clear reductions in the odds of highschool completion (adjusted odds ratio $0.37,95 \%$ CI $0.20-0.66)$ and degree attainment $(0 \cdot 38,0 \cdot 22-0.66)$, and substantially increased odds of later cannabis dependence $(17.95,9.44-34 \cdot 12)$, use of other illicit drugs $(7 \cdot 80,4 \cdot 46-13 \cdot 63)$, and suicide attempt $(6 \cdot 83,2 \cdot 04-22 \cdot 90)$.

Interpretation Adverse sequelae of adolescent cannabis use are wide ranging and extend into young adulthood. Prevention or delay of cannabis use in adolescence is likely to have broad health and social benefits. Efforts to reform cannabis legislation should be carefully assessed to ensure they reduce adolescent cannabis use and prevent potentially adverse developmental effects.

Funding Australian Government National Health and Medical Research Council.

\section{Introduction}

Marked shifts have taken place in attitudes to cannabis use. ${ }^{1}$ Moves to decriminalise or legalise cannabis use in several US states and Latin American countries are a sign of such changes in public opinion. ${ }^{2}$ These shifts have happened while debate continues about the long-term health and social sequelae of adolescent cannabis use., Additionally, in some countries adolescents are initiating cannabis use earlier than have those in previous years ${ }^{5}$ and more adolescents are using cannabis heavily. ${ }^{6-8}$ In England, 4\% of 11-15 year olds are past-month cannabis users; ${ }^{7}$ about $7 \%$ of US high-school seniors are daily or near-daily cannabis users; ${ }^{8}$ and in Australia, less than $1 \%$ of 14-19 year olds use daily and 4\% use weekly. ${ }^{6}$ This prevalence is particularly concerning because adolescence seems to be a vulnerable developmental period for the consequences of cannabis exposure, ${ }^{2}$ and evidence suggests that early use of cannabis is associated with increased risk of adverse developmental outcomes. ${ }^{10-14}$

Persisting questions about the long-term effects of adolescent cannabis use have clouded debate. ${ }^{12,15,16}$ The existing evidence has limitations, including limited statistical power to examine rarer outcomes and less common, more regular patterns of cannabis use than those already assessed; insufficient control for confounding; and a tendency to examine only one outcome or domain. As such, the picture of adolescent cannabis use and its putative health consequences is fractured. We address this issue through the integration of data from three large, long-running longitudinal studies from Australia and New Zealand: the Australian Temperament Project (ATP), ${ }^{17}$ the Christchurch Health and Development Study (CHDS), ${ }^{18}$ and the Victorian Adolescent Health Cohort Study (VAHCS). ${ }^{19}$

In this integrative meta-analysis, we examined the long-term sequelae of adolescent cannabis use on important domains of wellbeing during the transition to adulthood. Specifically, we aimed to develop similar measures of cannabis use and each outcome across all cohorts; examine the association between patterns of use before age 17 years and each outcome in combined data; and adjust the associations reported for a wide 
range of potential confounding factors drawn from similar domains across studies spanning individual, family, and peer characteristics and behaviours.

\section{Methods}

\section{Design and participants}

Integrative analyses were developed across the ATP, CHDS, and VAHCS (appendix). The analyses were based on data obtained over relevant assessments (appendix) between ages 13 and 30 years. We chose these cohorts because they had similar measures of cannabis use and outcomes that allowed effective harmonisation. We integrated participant-level data rather than using the more common meta-analytic approach of combining study-level estimates. This approach had at least three advantages: increased sample size and statistical precision, ${ }^{20,21}$ the opportunity to include a wide range of potential confounding factors, and the ability to provide a broad picture of the health and psychosocial consequences of adolescent cannabis use.

\section{Measures and outcomes}

Studies varied in measures used to assess cannabis use and outcomes, assessment period (eg, past month, past year), and timings of assessment. However, sufficient commonalities existed to enable integration of data ${ }^{22,23}$ and development of measures that were consistent across studies. ${ }^{22,23}$ We assessed seven outcomes in young people aged between 17 and 30 years, spanning educational attainment, substance use, mental health, and welfare dependence. The number of participants varied by outcome (from 2537 to 3765 participants). We chose the outcomes on the basis of previous research that established a link between a given outcome and cannabis use, and the availability of similar outcome measures across the cohorts. Derivation of the harmonised variables is summarised below, with additional information in the appendix. All dichotomous variables were coded as 0 for no and 1 for yes.

All studies included measures of frequency of cannabis use during mid-adolescence (appendix). We created a five-level measure of the maximum frequency of cannabis use before age 17 years (with 0 as never, 1 as less than monthly, 2 as monthly or more, 3 as weekly or more, and 4 as daily).

All studies obtained data for the completion of high school and university degree attainment. We created a dichotomous measure of high-school completion, and university degree attainment, both by age 25 years.

All studies included a measure of symptoms of cannabis dependence in the past 12 months. The CHDS and VAHCS assessed cannabis dependence with the Composite International Diagnostic Interview. The ATP obtained data for the frequency of five symptoms of cannabis dependence. We created a dichotomous measure of cannabis dependence in the past 12 months between ages 17 and 25 years.
All studies obtained data about use of other illicit drugs in the past month or past year from several categories: inhalants, hallucinogens, ecstasy, amphetamines, methamphetamines, heroin, cocaine, and non-medical use of prescription drugs. We created a dichotomous measure for use of other illicit drugs in the past month to the past year by ages $23-25$ years.

The CHDS assessed number of suicide attempts at yearly intervals from ages 17 to 25 years. The VAHCS used the Beck Self-harm Inventory at seven assessment times between ages 16 and 29 years (on average). On the basis of specific items, participants who reported selfharm with a serious intention to end life (eg, suicide attempt) were categorised. We created a dichotomous measure of any suicide attempt made between ages 17 and 25 years for the CHDS and VAHCS. The ATP did not assess suicidal behaviour.

The studies all used different measures to assess depression, and completed assessments at different ages. The CHDS used the Composite International Diagnostic Interview, the VAHCS used the Clinical Interview Schedule, and the ATP used the depression subscale from the short-form Depression Anxiety Stress Scale. We created a dichotomous measure of moderate or severe depression in the past week to the past month between ages 17 and 25 years.

The studies obtained data about present main source of income, including various categories of government support. Because patterns of income are not typically established until the late $20 \mathrm{~s},{ }^{24}$ we used data from the ATP at ages $27-28$ years, data from the VAHCS at age 29 years, and data from the CHDS at age 30 years. We created a dichotomous measure of present welfare dependence (excluding education-related government support) at ages 27-30 years.

We noted small between-study variations in the prevalence of adolescent cannabis use and some outcomes (appendix) that might be expected to be present in cohorts obtained from regions of similar cultural and sociodemographic backgrounds.

We selected potential confounding factors from each study on the basis of previous research suggesting that the variables might be correlated with both cannabis use and adverse psychosocial outcomes. These confounding factors spanned individual background and functioning, and parental and peer factors. Factors assessed antecedent to cannabis use were included when available. The appendix provides further information about potential confounding factors.

\section{Statistical analysis}

The analysis was based on an integrated dataset that combined participant-level data from the cohorts. The analysis was conducted in four stages. First, we estimated association between extent of adolescent cannabis use and each outcome with data from each study and from the combined dataset. This analysis examined associations
For more on the ATP see http:// www.aifs.gov.au/atp

See Online for appendix 


\begin{tabular}{|c|c|c|c|c|c|c|}
\hline & Never & Less than monthly & Monthly or more & Weekly or more & Daily & p value* \\
\hline \multicolumn{7}{|c|}{ High-school completion } \\
\hline ATP & 833/897 (93\%) & $89 / 100(89 \%)$ & $87 / 102(85 \%)$ & $24 / 35(69 \%)$ & $2 / 2(100 \%)$ & $<0.0001$ \\
\hline CHDS & $307 / 618(50 \%)$ & $106 / 276(38 \%)$ & $18 / 63(29 \%)$ & $11 / 82(13 \%)$ & $0 / 7$ & $<0.0001$ \\
\hline VAHCS & $851 / 977(87 \%)$ & $229 / 282(81 \%)$ & $74 / 90(82 \%)$ & 85/108 (79\%) & $24 / 39(62 \%)$ & $<0.0001$ \\
\hline Combined data & 1991/2492 (80\%) & $424 / 658(64 \%)$ & $179 / 255(70 \%)$ & $120 / 225(53 \%)$ & $26 / 48(54 \%)$ & $<0.0001$ \\
\hline \multicolumn{7}{|c|}{ Degree attainment } \\
\hline ATP & $359 / 734(49 \%)$ & $23 / 82(28 \%)$ & $22 / 74(30 \%)$ & $8 / 27(30 \%)$ & $0 / 3$ & $<0.0001$ \\
\hline CHDS & $181 / 596(30 \%)$ & $57 / 257(22 \%)$ & $11 / 63(18 \%)$ & $5 / 74(7 \%)$ & $0 / 7$ & $<0.0001$ \\
\hline VAHCS & $415 / 978(42 \%)$ & $89 / 283(32 \%)$ & $23 / 90(26 \%)$ & $13 / 108(12 \%)$ & 6/39 (15\%) & $<0.0001$ \\
\hline Combined data & $955 / 2308(41 \%)$ & $169 / 622(27 \%)$ & $56 / 227(25 \%)$ & $26 / 209(12 \%)$ & $6 / 49(12 \%)$ & $<0.0001$ \\
\hline \multicolumn{7}{|c|}{ Cannabis dependence } \\
\hline ATP & $25 / 600(4 \%)$ & $4 / 64(6 \%)$ & $10 / 55(18 \%)$ & $11 / 22(50 \%)$ & $2 / 2(100 \%)$ & $<0.0001$ \\
\hline CHDS & $17 / 619(3 \%)$ & $25 / 276(9 \%)$ & $12 / 64(19 \%)$ & $42 / 82(51 \%)$ & $6 / 7(86 \%)$ & $<0.0001$ \\
\hline VAHCS & 33/912 (4\%) & $27 / 259(10 \%)$ & $17 / 83(21 \%)$ & 45/99 (46\%) & $15 / 33(46 \%)$ & $<0.0001$ \\
\hline Combined data & 75/2131 (4\%) & $56 / 599(9 \%)$ & 39/202 (19\%) & $98 / 203(48 \%)$ & $23 / 42(55 \%)$ & $<0.0001$ \\
\hline \multicolumn{7}{|c|}{ Other illicit drug use } \\
\hline ATP & 88/738 (12\%) & $18 / 82(22 \%)$ & $17 / 75(23 \%)$ & $12 / 28(43 \%)$ & $1 / 3(33 \%)$ & $<0.0001$ \\
\hline CHDS & $80 / 596(13 \%)$ & $83 / 257(32 \%)$ & $29 / 6346 \%)$ & $31 / 74(42 \%)$ & $5 / 7(71 \%)$ & $<0.0001$ \\
\hline VAHCS & 41/972 (4\%) & $26 / 282(9 \%)$ & $19 / 89(21 \%)$ & $31 / 107(29 \%)$ & 9/39 (23\%) & $<0.0001$ \\
\hline Combined data & 209/2306 (9\%) & $127 / 621(21 \%)$ & $65 / 227(29 \%)$ & $74 / 209$ (35\%) & $15 / 49(31 \%)$ & $<0.0001$ \\
\hline \multicolumn{7}{|l|}{ Suicide attempt $\dagger$} \\
\hline CHDS & $26 / 619(4 \%)$ & $18 / 276(7 \%)$ & $6 / 64(9 \%)$ & $13 / 82(16 \%)$ & $1 / 7(14 \%)$ & $<0.001$ \\
\hline VAHCS & $3 / 972(<1 \%)$ & $1 / 282(<1 \%)$ & $4 / 90(4 \%)$ & $5 / 107(5 \%)$ & $1 / 38(3 \%)$ & $<0.001$ \\
\hline Combined data & 29/1591 (2\%) & 19/558 (3\%) & 10/154 (7\%) & $18 / 189(10 \%)$ & $2 / 45(4 \%)$ & $<0.001$ \\
\hline \multicolumn{7}{|l|}{ Depression } \\
\hline ATP & $47 / 898(5 \%)$ & 4/98 (4\%) & $2 / 102(2 \%)$ & $2 / 34(6 \%)$ & $1 / 3(33 \%)$ & 0.661 \\
\hline CHDS & 80/619 (13\%) & $48 / 276(17 \%)$ & $11 / 64(17 \%)$ & $20 / 82(24 \%)$ & $1 / 7(14 \%)$ & 0.006 \\
\hline VAHCS & $94 / 1041(9 \%)$ & $25 / 288(9 \%)$ & $13 / 100(13 \%)$ & $10 / 114(9 \%)$ & $5 / 39(13 \%)$ & 0.437 \\
\hline Combined data & $221 / 2558(9 \%)$ & $77 / 662(12 \%)$ & $26 / 266(10 \%)$ & $32 / 230(14 \%)$ & $7 / 49(14 \%)$ & 0.032 \\
\hline \multicolumn{7}{|c|}{ Welfare dependence $\ddagger$} \\
\hline ATP & $26 / 735(4 \%)$ & $5 / 83(6 \%)$ & $2 / 75(3 \%)$ & $0 / 32$ & $0 / 3$ & 0.491 \\
\hline CHDS & $41 / 581(7 \%)$ & $17 / 258(7 \%)$ & $4 / 61(7 \%)$ & $16 / 72(22 \%)$ & $3 / 7(43 \%)$ & $<0.0001$ \\
\hline VAHCS & $77 / 895$ (9\%) & $19 / 259(7 \%)$ & $10 / 90(11 \%)$ & 9/93 (10\%) & $4 / 40(10 \%)$ & 0.578 \\
\hline Combined data & $144 / 2211(7 \%)$ & $41 / 600(7 \%)$ & $16 / 226(7 \%)$ & 25/197 (13\%) & $7 / 50(14 \%)$ & 0.012 \\
\hline $\begin{array}{l}\text { Data are } n / N(\%) . ~ \\
\text { the association bet } \\
\text { behaviour. } ¥ \text { Assess }\end{array}$ & $\begin{array}{l}\text { alian Temperament } P \\
\text { lescent cannabis use } \\
28-30 \text { years. }\end{array}$ & $\begin{array}{l}\text { CHDS=Christchurch } \\
\text { ch outcome in each s }\end{array}$ & $\begin{array}{l}\text { and Developmer } \\
\text { and in combined }\end{array}$ & $\begin{array}{l}\text { VAHCS=Victori } \\
\text { sted for study-s }\end{array}$ & $\begin{array}{l}\text { ent Health C } \\
\text { cts. †The AT }\end{array}$ & $\begin{array}{l}\text { y. }{ }^{*} p \text { valu } \\
\text { ssess suic }\end{array}$ \\
\hline
\end{tabular}

between the extent of adolescent cannabis use and each outcome with data from each study and from the combined dataset. We tested associations for significance by fitting logistic regression models to the data from each study and from the combined dataset in which the log odds of each outcome were modelled as a linear function of the five-level measure of frequency of cannabis use. The models for the combined data were of the form: $\operatorname{logit}(Y i j)=B 0 j+B 1 X i j$ where logit $(Y i j)$ was the log odds of the outcome $Y$ for individual $i$ in study $j(j=1,2,3)$, and $\mathrm{Xij}$ was the corresponding frequency of cannabis use for individual $i$ in study $j$. The slope parameter for cannabis use (B1) was assumed to be constant across studies. However, the model included study-specific random intercepts (B0j) to allow for random sources of betweenstudy heterogeneity that were not otherwise represented in the model. We obtained effect-size estimates (odds ratios [ORs] and $95 \% \mathrm{CIs}$ ) for the combined data pooled over studies.

Second, we adjusted for covariates. To account for confounding factors, we extended the models in the first equation to include these factors. These models were of the form: logit $(Y i j)=B 0 j+B 1 X i j+\sum B k j Z i k j$ where $Z k j$ was a series of covariate factors representing the complete set of covariates across all studies j. Overall, we included 53 factors (appendix), but not all these covariates were measured by all studies. To address this inconsistency we developed a null covariate model. In this model if a 
covariate was not noted for any study, we set this covariate to a value of zero for that study. The advantage of this approach is that it included all the available data in the analysis. The appendix provides further information about this approach. We obtained estimates of the pooled adjusted ORs and $95 \%$ CIs.

The above models assumed a linear effect of cannabis use on the log odds of each outcome, and a common slope parameter (B1) for the effect of cannabis use across studies. To test these assumptions, we extended the above adjusted models in two ways. We first did Wald $\chi^{2}$ tests to examine the improvement in fit of a categorical representation of cannabis use over and above the linear model for each outcome. In all cases a linear model provided an adequate representation of the effect of cannabis use and no significant departures from linearity were detected. We then extended the models to allow the slope parameter for cannabis use (B1) to vary across studies, and then we did Wald $\chi^{2}$ tests to test for between-study heterogeneity in the effect of cannabis use. In all cases these tests were nonsignificant, suggesting that the assumption of a common slope was justified for all outcomes.

For the third stage of the statistical analysis, we did a sensitivity analysis. Although the null covariate model offered the advantage of enabling analysis of all available data, this method could have introduced study-specific biases. To examine the robustness of the null covariate model, we compared results with four alternative estimates of the adjusted ORs, which we derived with a harmonised covariate approach using a reduced set of covariates common to all studies; a covariate score approach in which we used the covariate information in each study to derive an optimum predictor of each outcome, and the single predictor score as a covariate in the combined data; a propensity score approach in which we used the covariate data in each study to derive a prediction model for adolescent cannabis use, and included the estimated propensity score as a covariate for each study; and a standard meta-analytic approach in which covariate-adjusted analyses were done separately for each study, and the study-level result then pooled meta-analytically (appendix). Fourth, we investigated the potential for selection bias. We used multiple imputation to examine the implications of possible selection bias attributable to sample attrition and missing data (appendix).

We did all analyses with STATA SE (version 13).

\section{Role of the funding source}

The sponsors of the study had no role in study design, data collection, data analysis, data interpretation, or writing of the report. The corresponding author had full access to all the data in the study and had final responsibility for the decision to submit for publication.

\section{Results}

Table 1 shows the associations between frequency of cannabis use before age 17 and the outcomes in young adults in each study and in the combined dataset, and the tests of significance from the fitted regression models for each outcome. At the individual study level, we recorded evidence of significant associations for all outcomes, except depression and welfare dependence in ATP and VAHCS (table 1). For the combined data, all associations were significant, with clear evidence of a dose-response association in which increasing frequency of adolescent cannabis use was associated with declining rates of highschool completion and degree attainment, and increasing risks of cannabis dependence, other illicit drug use, suicide attempt, depression, and welfare dependence. Table 2 and figure 1 show estimates of effect size for each level of cannabis use estimated from the regression model fitted to the combined data for each outcome.

We adjusted the associations in table 1 for confounding by adding the relevant covariates for each study with the null covariate adjustment approach. We included 53 covariate factors from the three studies in the analysis. These covariates spanned individual background and functioning, and measures of parental and peer factors (appendix). Table 2 and figure 2 show the adjusted ORs

\begin{tabular}{|c|c|c|c|c|c|c|c|}
\hline & Never & $\begin{array}{l}\text { Less than } \\
\text { monthly }\end{array}$ & $\begin{array}{l}\text { Monthly } \\
\text { or more }\end{array}$ & $\begin{array}{l}\text { Weekly } \\
\text { or more }\end{array}$ & Daily & p value & $\mathbf{N}$ \\
\hline \multicolumn{8}{|c|}{ Unadjusted odds ratios } \\
\hline $\begin{array}{l}\text { High-school } \\
\text { completion }\end{array}$ & 1 & $\begin{array}{l}0.67 \\
(0.62-0.73)\end{array}$ & $\begin{array}{l}0.45 \\
(0.38-0.54)\end{array}$ & $\begin{array}{l}0 \cdot 31 \\
(0 \cdot 24-0 \cdot 39)\end{array}$ & $\begin{array}{l}0.21 \\
(0.15-0.29)\end{array}$ & $<0.0001$ & 3678 \\
\hline $\begin{array}{l}\text { Degree } \\
\text { attainment }\end{array}$ & 1 & $\begin{array}{l}0.63 \\
(0.57-0.69)\end{array}$ & $\begin{array}{l}0 \cdot 40 \\
(0 \cdot 33-0 \cdot 48)\end{array}$ & $\begin{array}{l}0.25 \\
(0 \cdot 19-0 \cdot 33)\end{array}$ & $\begin{array}{l}0 \cdot 16 \\
(0.11-0 \cdot 23)\end{array}$ & $<0.0001$ & 3415 \\
\hline $\begin{array}{l}\text { Cannabis } \\
\text { dependence }\end{array}$ & 1 & $\begin{array}{l}2.75 \\
(2.48-3.06)\end{array}$ & $\begin{array}{l}7 \cdot 58 \\
(6 \cdot 14-9 \cdot 36)\end{array}$ & $\begin{array}{l}20 \cdot 87 \\
(15 \cdot 20-28.64)\end{array}$ & $\begin{array}{l}57 \cdot 45 \\
(37.66-87.64)\end{array}$ & $<0.0001$ & 3177 \\
\hline $\begin{array}{l}\text { Other illicit } \\
\text { drug use }\end{array}$ & 1 & $\begin{array}{l}1.82 \\
(1.66-1.99)\end{array}$ & $\begin{array}{l}3 \cdot 31 \\
(2 \cdot 77-3 \cdot 94)\end{array}$ & $\begin{array}{l}6 \cdot 01 \\
(4 \cdot 61-7 \cdot 83)\end{array}$ & $\begin{array}{l}10.93 \\
(7 \cdot 68-15 \cdot 55)\end{array}$ & $<0.0001$ & 3412 \\
\hline $\begin{array}{l}\text { Suicide } \\
\text { attempt* }^{*}\end{array}$ & 1 & $\begin{array}{l}1.72 \\
(1.43-2 \cdot 06)\end{array}$ & $\begin{array}{l}2 \cdot 94 \\
(2 \cdot 04-4 \cdot 24)\end{array}$ & $\begin{array}{l}5.05 \\
(2.92-8 \cdot 74)\end{array}$ & $\begin{array}{l}8.66 \\
(4.17-18.01)\end{array}$ & $<0.0001$ & 2537 \\
\hline Depression & 1 & $\begin{array}{l}1.12 \\
(1.01-1.25)\end{array}$ & $\begin{array}{l}1.26 \\
(1.02-1 \cdot 56)\end{array}$ & $\begin{array}{l}1.42 \\
(1.03-1.94)\end{array}$ & $\begin{array}{l}1.59 \\
(1 \cdot 04-2 \cdot 42)\end{array}$ & 0.032 & 3765 \\
\hline $\begin{array}{l}\text { Welfare } \\
\text { dependence } †\end{array}$ & 1 & $\begin{array}{l}1 \cdot 17 \\
(1 \cdot 04-1 \cdot 32)\end{array}$ & $\begin{array}{l}1 \cdot 37 \\
(1.07-1 \cdot 75)\end{array}$ & $\begin{array}{l}1 \cdot 61 \\
(1 \cdot 11-2 \cdot 32)\end{array}$ & $\begin{array}{l}1 \cdot 88 \\
(1.15-3 \cdot 07)\end{array}$ & 0.012 & 3284 \\
\hline \multicolumn{8}{|c|}{ Adjusted odds ratios } \\
\hline $\begin{array}{l}\text { High-school } \\
\text { completion }\end{array}$ & 1 & $\begin{array}{l}0.78 \\
(0.67-0.90)\end{array}$ & $\begin{array}{l}0.61 \\
(0.45-0.81)\end{array}$ & $\begin{array}{l}0 \cdot 47 \\
(0.30-0.73)\end{array}$ & $\begin{array}{l}0.37 \\
(0.20-0.66)\end{array}$ & 0.001 & 3004 \\
\hline $\begin{array}{l}\text { Degree } \\
\text { attainment }\end{array}$ & 1 & $\begin{array}{l}0.78 \\
(0.69-0.90)\end{array}$ & $\begin{array}{l}0.62 \\
(0.47-0.81)\end{array}$ & $\begin{array}{l}0.49 \\
(0.32-0.73)\end{array}$ & $\begin{array}{l}0.38 \\
(0.22-0.66)\end{array}$ & $<0.0001$ & 2834 \\
\hline $\begin{array}{l}\text { Cannabis } \\
\text { dependence }\end{array}$ & 1 & $\begin{array}{l}2 \cdot 06 \\
(1 \cdot 75-2 \cdot 42)\end{array}$ & $\begin{array}{l}4 \cdot 24 \\
(3 \cdot 07-5 \cdot 84)\end{array}$ & $\begin{array}{l}8 \cdot 72 \\
(5 \cdot 39-14 \cdot 12)\end{array}$ & $\begin{array}{l}17.95 \\
(9.44-34.12)\end{array}$ & $<0.0001$ & 2675 \\
\hline $\begin{array}{l}\text { Other illicit } \\
\text { drug use }\end{array}$ & 1 & $\begin{array}{l}1.67 \\
(1.45-1.92)\end{array}$ & $\begin{array}{l}2 \cdot 79 \\
(2 \cdot 11-3 \cdot 69)\end{array}$ & $\begin{array}{l}4 \cdot 67 \\
(3 \cdot 07-7 \cdot 10)\end{array}$ & $\begin{array}{l}7 \cdot 80 \\
(4 \cdot 46-13.63)\end{array}$ & $<0.0001$ & 2832 \\
\hline $\begin{array}{l}\text { Suicide } \\
\text { attempt* }^{*}\end{array}$ & 1 & $\begin{array}{l}1.62 \\
(1 \cdot 19-2 \cdot 19)\end{array}$ & $\begin{array}{l}2 \cdot 61 \\
(1 \cdot 43-4.79)\end{array}$ & $\begin{array}{l}4 \cdot 23 \\
(1 \cdot 71-10.47)\end{array}$ & $\begin{array}{l}6.83 \\
(2.04-22.90)\end{array}$ & 0.002 & 2192 \\
\hline Depression & 1 & $\begin{array}{l}1.01 \\
(0.85-1.19)\end{array}$ & $\begin{array}{l}1 \cdot 01 \\
(0 \cdot 72-1 \cdot 42)\end{array}$ & $\begin{array}{l}1.02 \\
(0.61-1.69)\end{array}$ & $\begin{array}{l}1 \cdot 02 \\
(0.52-2 \cdot 01)\end{array}$ & 0.946 & 2927 \\
\hline $\begin{array}{l}\text { Welfare } \\
\text { dependence } \dagger\end{array}$ & 1 & $\begin{array}{l}1.04 \\
(0.84-1.28)\end{array}$ & $\begin{array}{l}1.08 \\
(0.71-1.63)\end{array}$ & $\begin{array}{l}1.12 \\
(0.60-2 \cdot 09)\end{array}$ & $\begin{array}{l}1.16 \\
(0 \cdot 50-2 \cdot 66)\end{array}$ & 0.727 & 2664 \\
\hline
\end{tabular}

Data are odds ratios $(95 \% \mathrm{Cls})$. Only the Christchurch Health and Development Study and the Victorian Adolescent Health Cohort Study assessed suicidal behaviour. $†$ Assessed at age $28-30$ years.

Table 2: Maximum frequency of cannabis use before age 17 years, and each young adult outcome in combined data, before and after adjustment with the null covariate approach 
Figure 1: Unadjusted odds ratios (log scale) between maximum frequency of cannabis use before age 17 years and young adult outcomes in combined data, compared with individuals who have never used cannabis Error bars show 95\% Cls.

Figure 2: Adjusted odds ratios (log scale) between maximum frequency of cannabis use before age 17 years and young adult outcomes in combined data, compared with individuals who have never used cannabis Error bars show $95 \% \mathrm{Cls}$.
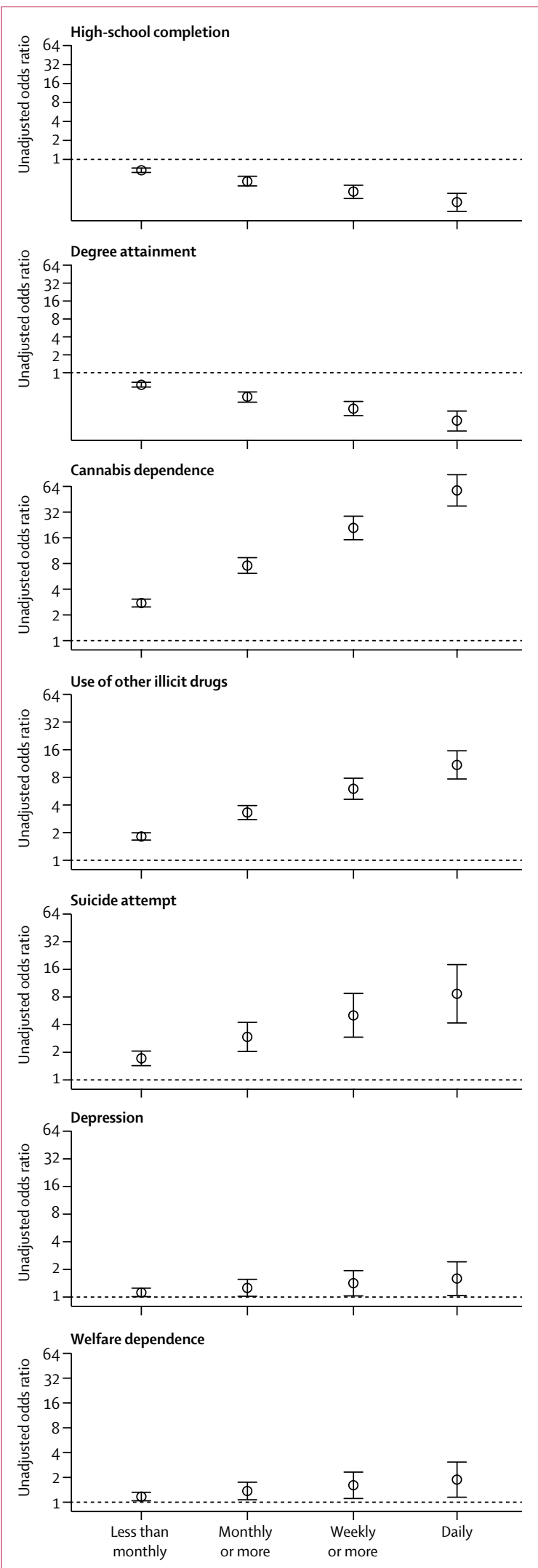
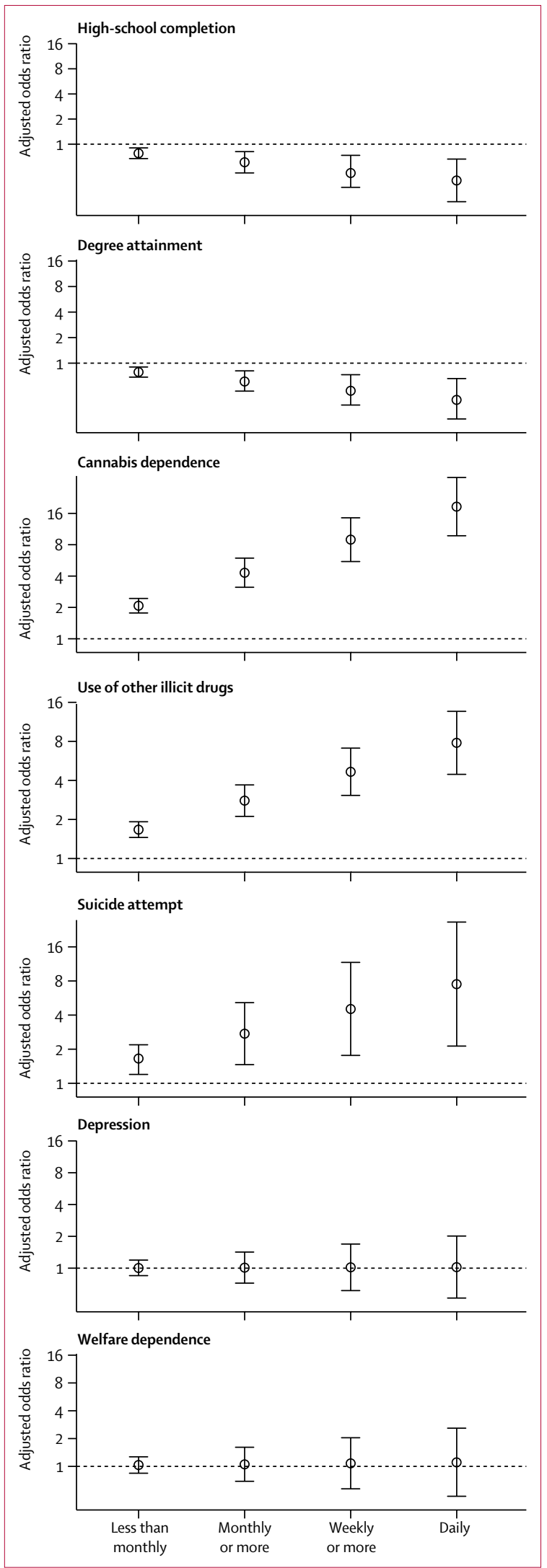
between the extent of cannabis use and each outcome in the combined data. After adjustment, the associations for depression and welfare dependence were both nonsignificant and negligible in size (table 2). For all other outcomes the associations remained significant (table 2). The estimates for adjusted ORs suggested that individuals who were daily users before age 17 years had odds of high-school completion and degree attainment that were $63 \%$ and $62 \%$ lower, respectively, than those who had never used cannabis; furthermore, daily users had odds of later cannabis dependence that were 18 times higher, odds of use of other illicit drugs that were eight times higher, and odds of suicide attempt that were seven times higher (table 2, figure 2).

Results of Wald $\chi^{2}$ tests of between-study heterogeneity in the effect of cannabis use were non-significant (data not shown), suggesting that the associations were similar across studies for all outcomes.

To examine the sensitivity of the results for adjusted ORs in table 2 to choice of model for adjusting covariates, we repeated the analyses with four alternative approaches to covariate adjustment: harmonised covariate, covariate score, propensity score, and standard meta-analysis (appendix). The findings from table 2 were replicated by these analyses, showing that the results were not dependent on the methodology used to estimate the covariate-adjusted associations. Further analysis using multiple imputation of missing data to control for potential sample selection bias produced findings that were entirely consistent with those of the recorded data (appendix).

\section{Discussion}

Our findings show clear and consistent associations between the frequency of adolescent cannabis use and all adverse young adult outcomes. These associations had dose-response characteristics across all seven outcomes, with the strongest effects shown for daily users. For all but two outcomes, associations were resilient to control for the range of potential confounding factors assessed. With control for potential observed confounders, the strength of association substantially reduced, and five of the outcomes remained significant. After adjustment, individuals who had used cannabis daily before age 17 years had odds of high-school completion and degree attainment that were lower than those who had never used cannabis before age 17 years, and higher odds of cannabis dependence, use of other illicit drugs, and suicide attempt. Results were robust to four alternative approaches to covariate adjustment and imputation of missing data.

Several aspects of the study findings support the possibility of a causal relation. First, we recorded strong associations between adolescent cannabis use and all young adult outcomes investigated. Second, the associations had dose-response characteristics with increasing frequency of adolescent use. Third, most associations were resilient to control for potential confounding factors present before and during adolescence. Studies such as ours are limited in their capacity to explain the mechanisms behind such associations, although some research has suggested that heavy cannabis use in adolescence might affect CNS development; 9 alternatively, cannabis use in adolescence could be a marker of developmental trajectories that place young people at increased risk of adverse psychosocial outcomes. ${ }^{25}$ Study findings in relation to high-school completion, university degree attainment, cannabis dependence, and use of other illicit drugs are consistent with previous research investigating the association between early cannabis use and these outcomes. . $^{10,12,13,23}$ Although the association between cannabis use and high-school completion probably does not arise from a reverse causal association (school dropout leading to cannabis use), ${ }^{26}$ this possibility remains plausible. ${ }^{10}$ The strong adjusted effects noted for suicide attempt add to a small body of research that supports a more direct relation between cannabis use and suicidal ideation. ${ }^{27}$ Depression and welfare dependence were not significantly associated with adolescent cannabis use after adjustment. This finding is consistent with previous reviews, which concluded that the effect of cannabis use on these psychosocial outcomes could plausibly be explained by

\section{Panel: Research in context}

\section{Systematic review}

We did a review of systematic reviews published since the key 2004 paper by Macleod and colleagues. ${ }^{15}$ We searched Medline, Global Health, Embase, PsycINFO, and PsycARTICLES with the terms "cannabis or marijuana" and "systematic review" for reports about the effect of cannabis use on psychosocial outcomes (eg, school or university completion, welfare dependence), cannabis dependence, use of other illicit drugs, depression, and suicide. We identified 290 non-duplicate reports, of which nine focused on our key outcomes. Both cross-sectional and longitudinal data link cannabis use with high-school dropout, although reverse causality (dropout leading to cannabis use) remains plausible. ${ }^{10}$ Although no review of welfare dependence was identified, existing data from our study cohorts link cannabis use with welfare dependence and unemployment. ${ }^{11}$ Use of cannabis is associated with development of both cannabis dependence and use of other illicit drugs..$^{12,13}$ Although a causal association with depression is in doubt, ${ }^{12,16}$ heavy use in particular, increases the odds of depression. ${ }^{14}$ Initial reports also suggest that prenatal exposure effects subsequent depression. ${ }^{34}$ Presently, evidence is insufficient to cite a causal link with suicide. ${ }^{35}$

\section{Interpretation}

Study findings suggest that adolescent cannabis use is linked to difficulties in successfully completing the tasks that mark the transition to adulthood. Prevention or delay of cannabis use in adolescence is likely to have broad health and social benefits. The findings are relevant given the movement in some countries to decriminalise or legalise cannabis raising a possibility that cannabis might become more accessible to young people. In the rapidly changing political and legislative landscape, protection of adolescents from the potential adverse effects of cannabis use is an important facet of legislative reforms for cannabis. Efforts to reform cannabis legislation should be carefully assessed to ensure they reduce adolescent cannabis use and prevent potentially adverse effects on adolescent development. 
potential confounding factors that had not been adequately controlled for in studies to date. . $^{15,16}$

This study has some limitations. First, there was some between-study variation in the levels of the outcomes, which could have been shown by variations in estimates of effect size across studies. However, such estimates were very similar, with Wald tests providing no evidence of significant between-study heterogeneity. Second, the criteria for depression in the Australian Temperament Study were weaker than those in other studies. However, irrespective of the way in which depression was measured, the same conclusion holds. Third, although we controlled for many potential confounding factors, the possibility that the recorded associations might show the effects of unmeasured or uncontrolled confounding cannot be completely ruled out. ${ }^{15}$ Residual confounding could attenuate the associations. However, analyses that have used fixed-effects regression to control for non-observed confounders suggest that associations between cannabis use and various outcomes persist. ${ }^{28,29}$ Methods of fixedeffects regression ${ }^{30}$ provide a means to control for nonobserved fixed sources of confounding of the associations between an exposure variable and an outcome in repeated measures data. Fourth, measures were obtained by selfreport, which might be subject to socially desirable response bias, the extent of which can vary with age. ${ }^{31}$ Presence of such bias could lead to over-reporting or under-reporting of cannabis use. In face-to-face settings (as is generally the case for the cohorts in this study) adolescents might be more likely than adults to underreport risk behaviours; ${ }^{31}$ however, under-reporting would attenuate any observable associations. Fifth, similarities in the cultural and social context and epidemiology of cannabis use between Australia and New Zealand suggest that results can be applied to Australasian populations. Because rates of cannabis use in young people in Australasia are similar to those in other high-income countries (eg, in the USA, Canada, and the UK), ${ }^{32,33}$ generalisability of findings to those settings is supported. Nevertheless, the social and legislative context of cannabis use varies between regions, ${ }^{2}$ and remains an important consideration in the generalisation of these findings.

This study extends previous research of the link between adolescent cannabis use and problems later in life by the integration of data from various sources and the provision of control for a broader range of covariates than possible in traditional meta-analyses. The findings provide evidence of the potential harms of adolescent cannabis use across several domains. The prevention or delay of cannabis use in adolescence might have broad health and social benefits. The findings are particularly relevant as the movement to decriminalise or legalise cannabis gathers momentum in a number of countries (panel). ${ }^{2}$ Research suggests that such changes could lead to an increase in cannabis use mainly through a reduction in price. ${ }^{36}$ Although the effect of cannabis prices on the intensity and duration of cannabis use is unclear, ${ }^{36}$ evidence suggests that lower prices might lead to earlier onset of use..$^{37}$ This hypothesis is concerning because the adolescent brain is vulnerable to the effects of cannabis $^{9}$ and, as our findings suggest, cannabis use in adolescence is associated with increased risk of adverse developmental outcomes. In the rapidly changing political and legislative landscape, protection of adolescents from the potentially adverse effects of cannabis use is an important facet of cannabis legislative reforms. Despite increased availability of cannabis (for medical use) in some US states, a study ${ }^{38}$ showed no increase in use among young people in those states. Nonethelss, efforts to reform cannabis legislation should be carefully assessed to ensure they reduce adolescent cannabis use and prevent potentially adverse developmental effects.

\section{Contributors}

GCP, LD, DMF, and LJH conceptualised and designed the study. LJH, GCP, CAO, DMF, JWT, CC, and PL acquired the data. ESi, LJH, CAO, ESp, and DMH did the data analysis. All investigators, except PL, contributed to data interpretation. ESi, DMF, GCP, LJH, LD, CAO $\mathrm{DMH}$, and ESp drafted sections of the report. All investigators critically revised the paper and approved the final version for publication.

\section{The Cannabis Cohorts Research Consortium}

Steve Allsop (National Drug Research Institute, Curtin University, Perth, WA, Australia); Wayne Hall (UQ Centre for Clinical Research, University of Queensland, Brisbane, QLD, Australia); Reza Hayatbakhsh (School of Population Health, University of Queensland, Brisbane, QLD, Australia) Kerriann Little (Melbourne School of Psychological Sciences and Department of Paediatrics, University of Melbourne, Parkville, VIC, Australia; Murdoch Childrens Research Institute, Royal Children's Hospital, Parkville, VIC, Australia); Jake Najman (School of Social Science, University of Queensland, Brisbane, QLD, Australia); Rachel Skinner (Sydney University Discipline of Paediatrics and Child Health, Children's Hospital at Westmead, Sydney, Australia; Telethon Kids Institute, Subiaco, WA, Australia); and Tim Slade (National Drug and Alcohol Research Centre and Centre for Research Excellence in Mental Health and Substance Use, UNSW Australia, Sydney, NSW, Australia).

\section{Declaration of interests}

We declare no competing interests.

\section{Acknowledgments}

This study was supported by an Australian Government National Health and Medical Research Council Project Grant (number 1009381). The National Drug and Alcohol Research Centre and the National Cannabis Prevention and Information Centre at UNSW Australia, Sydney, Australia are supported by funding from the Australian Government. GCP is supported by an National Health and Medical Research Council (NHMRC) senior principal research fellowship (APP1019887). DMH is supported by a vice-chancellor's postdoctoral fellowship from the UNSW. LD (APP1041742) and RPM (APP1045318) are each supported by an NHMRC principal research fellowship. We thank all individuals and families involved in the participating cohorts for their time and invaluable contribution to the study: all collaborators who have contributed to the Australian Temperament Project, especially Ann Sanson, Diana Smart, Margot Prior, and Frank Oberklaid; and Christina O'Loughlin, John Carlin, and Helen Romaniuk for their contributions to the Victorian Adolescent Health Cohort.

\section{References}

1 Benac N, Caldwell A. Marijuana legalization gains support confounding policymakers. June 29, 2013. http://www. huffingtonpost.com/2013/06/29/marijuana-legalization_n_3521547. html (accessed Jan 28, 2014).

2 Reuter P. Marijuana legalization: what can be learned from other countries. Baltimore, MD: RAND Drug Policy Research Center University of Maryland, 2010

3 Burden W. Opinion: legalization of marijuana has financial, health benefits. Jan 21, 2014. http://thelantern.com/2014/01/ opinion-legalization-marijuana-financial-health-benefits / (accessed Jan 28, 2014). 
4 Richards S. Is cannabis really that bad? Jan 23, 2013. http://www. the-scientist.com/?articles.view/articleNo/34110/title/Is-CannabisReally-That-Bad-/ (accessed Jan 28, 2014).

5 Johnston L, O'Malley P, Bachman J, Schulenberg J. Monitoring the future national survey results on drug use, 1975-2010: secondary school students. 2011. http://files.eric.ed.gov/fulltext/ED528081.pdf (accessed Jan 28, 2014).

6 Australian Institute of Health and Welfare (AIHW). 2010 National drug strategy household survey report. Canberra: AIHW, 2011.

7 Henderson H, Nass L, Payne C, Phelps A, Ryley, A. Smoking, drinking and drug use among young people in England in 2012. London: Health and Social Care Information Centre, 2013.

8 Johnston LD, O'Malley P, Bachman J, Schulenberg J. Monitoring the future national results on drug use: 2012 overview, key findings on adolescent drug use. Institute for Social Research, University of Michigan: Ann Arbor, 2013.

9 Schneider M. Puberty as a highly vulnerable developmental period for the consequences of cannabis exposure. Addict Biol 2008; 13: 253-63.

10 Townsend L, Flisher A, King G. A systematic review of the relationship between high school dropout and substance use. Clin Child Fam Psychol 2007; 10: 295-317.

11 Fergusson D, Boden J. Cannabis use and later life outcomes. Addiction 2008; 103: 969-76.

12 Degenhardt L, Hall W. Extent of illicit drug use and dependence, and their contribution to the global burden of disease. Lancet 2012; 379: 55-70.

13 Fryers T, Brugha T. Childhood determinants of adult psychiatric disorder. Clin Pract Epidemiol Ment Health 2013; 9: 1-50.

14 Lev-Ran S, Roerecke M, Le Foll B, George T, McKenzie K, Rehm J. The association between cannabis use and depression: a systematic review and meta-analysis of longitudinal studies. Eur Psychiatry 2013; 28: 797-810.

15 Macleod J, Oakes R, Copello A, et al. Psychological and social sequelae of cannabis and other illicit drug use by young people: A systematic review of longitudinal, general population studies. Lancet 2004; 363: 1579-88.

16 Moore THM, Zammit S, Lingford-Hughes A, et al. Cannabis use and risk of psychotic or affective mental health outcomes: a systematic review. Lancet 2007; 370: 319-28.

17 Vassallo S, Sanson A. The Australian Temperament Project: the first 30 years. Melbourne: Australian Institute of Family Studies, 2013.

18 Fergusson D, Horwood L. The Christchurch Health and Development Study: review of findings on child and adolescent mental health. Aust N Z J Psychiatry 2001; 35: 287-96.

19 Patton G, Coffey C, Lynsky M, et al. Trajectories of adolescent alcohol and cannabis use into young adulthood. Addiction 2007; 102: 607-15.

20 Curran P, Hussong A. Integrative data analysis: the simultaneous analysis of multiple data sets. Psychol Methods 2009; 14: 81-100.

21 Hofer S, Piccinin A. Integrative data analysis through coordination of measurement and analysis protocol across independent longitudinal studies. Psychol Methods 2009; 14: 150-64.
22 Horwood J, Fergusson D, Coffey C, et al. Cannabis and depression: an integrative data analysis of four Australasian cohorts. Drug Alcohol Depend 2012; 126: 369-78.

23 Horwood J, Fergusson DM, Hayatbakhsh M, et al. Cannabis use and educational achievement: findings from three Australasian cohort studies. Drug Alcohol Depend 2010; 110: 247-53.

24 Arnett J. Emerging adulthood: What is it, and what is it good for? Child Dev Perspect 2007; 1: 68-73.

25 Kandel D, Davies M, Karus D, Yamaguchi K. The consequences in young adulthood of adolescent drug involvement. Arch Gen Psychiatry 1986; 43: 746-54.

26 Fergusson D, Horwood L, Beautrais A. Cannabis and educational achievement. Addiction 2003; 98: 1681-92.

27 Van Ours JC, Williams J, Fergusson D, Horwood J. Cannabis use and suicidal ideation. $J$ Health Econ 2013; 32: 524-37.

28 Fergusson D, Horwood L, Swain-Campbell N. Cannabis dependence and psychotic symptoms in young people. Pychol Medicine 2003; 33: 15-21.

29 Fergusson D, Horwood L, Ridder E. Tests of causal linkages between cannabis use and psychotic symptoms. Addiction 2005; 100: 354-66.

30 Fergusson D, Swain-Campbell N, Horwood L. Deviant peer affiliations, crime and substance use: a fixed effects regression analysis. J Abnorm Child Psychol 2002; 30: 419-30.

31 Brener N, Billy J, Grady W. Assessment of factors affecting the validity of self-reported health-risk behavior among adolescents: evidence from the scientific literature. J Adolesc Health 2003; 33: 436-57.

32 UNICEF Office of Research. Child well-being in rich countries: a comparative overview. Florence: UNICEF Office of Research, 2013.

33 Henderson H, Nass L, Payne C, Phelps A, Ryley A. Smoking, drinking and drug use among young people in England in 2012 London: Health and Social Care Information Centre, 2013.

34 Williams JH, Ross L. Consequences of prenatal toxin exposure for mental health in children and adolescents: a systematic review. Eur Child Adolesc Psychiatry 2007; 16: 243-53.

35 Calabria B, Degenhardt L, Hall W, Lynskey M. Does cannabis use increase the risk of death? Systematic review of epidemiological evidence on adverse effects of cannabis use. Drug Alcohol Rev 2010; 29: 318-30.

36 Caulkins J, Kilmer B, MacCoun R, Pacula R, Reuter P. Design considerations for legalizing cannabis: lessons inspired by analysis of California's Proposition 19. Addiction 2011; 107: 865-71.

37 van Ours JC, Williams J. Cannabis prices and dynamics of cannabis use. J Health Econ 2007; 26: 578-96.

38 Choo EK, Benz M, Zaller N, Warren O, Rising KL, McConnell KJ. The impact of state medical marijuana legislation on adolescent marijuana use. J Adolesc Health 2014; 55: 160-66. 


\section{Adolescent cannabis use and adverse sequelae in adulthood}

Present or previous cannabis use is more common in individuals with low educational attainment than in those with higher levels of educational achievement. Debate surrounds whether this association is attributable to cannabis use being more frequent in socioeconomic groups that are more likely to have poor educational attainment, whether cannabis use is actually a marker of an already established disadvantageous development, or whether the association is a truly causal one. ${ }^{1}$

In The Lancet Psychiatry, Edmund Silins and colleagues' integrative meta-analysis ${ }^{2}$ assesses the long-term psychosocial sequelae of adolescent cannabis use. The report, which is based on participant-level data from three studies from Australia and New Zealand, clearly shows a dose-response association between frequency of cannabis use in adolescence and ability to complete specific tasks that mark the transition to adulthood, specifically the ability to achieve high levels of education. After confounder control, individuals who were daily users before age 17 years had reductions in the odds of high-school completion (adjusted odds ratio [OR] $0.37,95 \% \mathrm{Cl} 0.20-0.66)$ and degree attainment (0.38, 0.22-0.66) compared with those who had never used cannabis. Furthermore, cannabis use was associated with increased risk of suicide attempt (adjusted OR 6.83, 95\% Cl 2.04-22.90) and, unsurprisingly, later cannabis dependence $(17.95,9.44-34.12)$ and use of other illicit

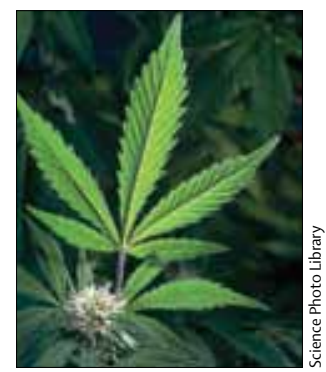

See Articles page 286 
drugs $(7.80,4.46-13.63)$. The participation rate in the study is impressive, the attrition rates are modest, and the number of confounding factors, assessed across cohorts, is overwhelming and covers a broad range of factors that could affect outcome independently.

Persistent cannabis use has adverse effects, such as low energy and initiative, and impairment of cognitive functions, and these factors are likely to mediate the harmful effect of cannabis on educational attainment. Findings from randomised clinical trials show a negative short-term effect of cannabis intake compared with placebo on cognitive function during, and in the hours following, intoxication. Compared with placebo, dronabinol impaired working memory and verbal fluency in a trial ${ }^{3}$ involving 22 healthy volunteers. In another trial ${ }^{4}$ with 30 healthy participants, Morrison and colleagues showed that working memory and executive functions were reduced by $10-20 \%$ in participants randomised to receive dronabinol.

A randomised clinical trial that exposes some young people to cannabis in various doses for a long term and compares them with other young people given placebo will never be done. Therefore, findings from naturalistic experiments will be relied on to obtain knowledge about whether the harmful effect on cognitive function is temporary. Increasing evidence shows that brain development during adolescence can be harmed by frequent cannabis use, and cognitive functions can be permanently reduced. In the Dunedin birth cohort $^{5}$ cognitive function was examined at age 13 years and again at age 38 years. Continuous cannabis use was associated with neuropsychological decline across all domains of cognitive functioning, and more persistent use was associated more severe decline. Additionally, adolescent-onset cannabis users were more impaired than adult-onset users and neuropsychological functioning in adolescent-onset users was not fully restored after cessation. The investigators concluded that their findings were suggestive of a neurotoxic effect of cannabis on the adolescent brain.

In a review, ${ }^{6}$ Schweinsburg and colleagues concluded that studies of adolescents who were heavy marijuana users showed that there were still persisting deficits at least 6 weeks after discontinuation, particularly in the domains of learning, memory, and working memory.
Moreover, cognitive functions were more severely affected in adolescents than in adults.

Cannabis use in adolescence has also been associated with increased risk of psychosis in adulthood. Cannabis use is associated with earlier onset of psychosis, ${ }^{8}$ and in patients with cannabis use and psychosis, risk of continuous psychotic symptoms is higher in those who continue to use cannabis than in those who stop.?

The convincing results presented by Silins and colleagues $^{2}$ are very valuable and highly appropriate at a time when several American states and countries in Latin America and Europe have decriminalised or legalised cannabis and allow unrestricted marketing of various formulations of the drug. Such changes in legislation will probably be followed by decreased prices and increased use, which will lead to more young people having difficulties with school completion and social and personal maturation, and will increase the risk of psychosis.

Youth is a very vulnerable period in life. Socially, young people need to develop and mature, and to prepare themselves to meet demands in their adult life, such as completing education and finding employment, choosing leisure activities, and finding partners and friends. Cannabis use, especially frequent uses, impairs this development and reduces the likelihood that a young person will be able to establish a satisfactory adult life.

\section{Merete Nordentoft}

University of Copenhagen, Mental Health Center Copenhagen, Mental Health Services in the Capital Region of Denmark,

Copenhagen 2400, Denmark

mn@dadlnet.nk

I declare no competing interests.

1 Macleod J, Oakes R, Copello A, et al. Psychological and social sequelae of cannabis and other illicit drug use by young people: a systematic review of longitudinal, general population studies. Lancet 2004; 363: 1579-88

2 Silins E, Horwood LJ, Patton GC, for the Cannabis Cohorts Research Consortium. Young adult sequelae of adolescent cannabis use: an integrative meta-analysis. Lancet Psychiatry 2014; 1: 286-93.

3 D'Souza DC, Perry E, Macdougall L, et al. The psychotomimetic effects of intravenous delta-9-tetrahydrocannabinol in healthy individuals: implications for psychosis. Neuropsychopharmacology 2004; 29: $1558-72$

4 Morrison PD, Zois V, McKeown DA, et al. The acute effects of synthetic intravenous Delta9-tetrahydrocannabinol on psychosis, mood and cognitive functioning. Psychol Med 2009; 39: 1607-16.

5 Meier MH, Caspi A, Ambler A, et al. Persistent cannabis users show neuropsychological decline from childhood to midlife. Proc Natl Acad Sci USA 2012; 109: E2657-64.

6 Schweinsburg AD, Brown SA, Tapert SF. The influence of marijuana use on neurocognitive functioning in adolescents. Curr Drug Abuse Rev 2008; 1: 99-111. 